\title{
Sextant
}

Revue de recherche interdisciplinaire sur le genre et la sexualité

35 | 2018

Striges en tous genres

\section{Michel Vincineau, homme de droit, de combats, de cœur, de passions et de plume}

Eric David, Jean Salmon et Annemie Schaus

\section{OpenEdition}

\section{Journals}

Édition électronique

URL : https://journals.openedition.org/sextant/409

DOI : $10.4000 /$ sextant.409

ISSN : 2795-8736

Éditeur

Éditions de l'Université de Bruxelles

\section{Édition imprimée}

Date de publication : 1 décembre 2018

Pagination : 161-162

ISBN : 978-2-8004-1636-6

ISSN : $1370-267 X$

Référence électronique

Eric David, Jean Salmon et Annemie Schaus, « Michel Vincineau, homme de droit, de combats, de cœur, de passions et de plume », Sextant [En ligne], 35 | 2018, mis en ligne le 01 novembre 2021 consulté le 08 décembre 2021. URL : http://journals.openedition.org/sextant/409; DOI : https:// doi.org/10.4000/sextant.409

\section{(c) (i) (2)(2)}

La revue Sextant est mise à disposition selon les termes de la Licence Creative Commons Attribution Pas d'Utilisation Commerciale - Partage dans les Mêmes Conditions 4.0 International 


\title{
Michel Vincineau, homme de droit, de combats, de cœur, de passions et de plume'
}

\author{
Eric DaVID, Jean SALMon et Annemie Schaus
}

S'il est parti avec discrétion, Michel Vincineau laissera une trace profonde, tant dans la mémoire de l'UlB que de la vie bruxelloise. Après des études secondaires à l'Athénée de Morlanwelz, il poursuit son cursus universitaire à l'UlB où il sera successivement docteur en droit (1963), licencié en droit international (1964), licencié en Sciences politiques et diplomatiques (1966). Jean Salmon, le directeur du tout nouveau Centre de droit international de l'Université, remarque ce brillant étudiant et l'engage comme chercheur. Ce centre demeurera le foyer de sa vie académique. Il y assurera notamment le secrétariat de la Revue belge de droit international de 1974 à 1983, dont il animera en particulier - et dirigera pendant plusieurs années la Chronique de la pratique belge du gouvernement et des chambres législatives en matière de droit international.

Michel Vincineau fut également chargé de divers enseignements : droit international de l'air et de l'espace, questions de droit international public relatives à l'Europe, droit de la mer, droit de la coopération, entre autres. Parmi ses écrits, on retiendra un ouvrage publié dans les années 1970 qui lui valut un succès qui dépassa le petit landerneau du monde académique : La Belgique et le commerce des armes. Paru en 1974 aux éditions Vie ouvrière, l'ouvrage dénonçait l'application ambiguë par la Belgique de sa législation applicable à cette matière. De nombreuses publications concernèrent également la conservation de l'environnement, la pollution par les hydrocarbures, le trompe-l'œil du désarmement, la bombe à neutrons, les armes bactériologiques, biologiques (ou à toxines), diverses luttes pour l'autodétermination des peuples, les droits des travailleurs émigrés, le seuil de l'illicite dans le principe de non-intervention...

\footnotetext{
1 Publié dans Esprit libre, 48, 2017, p. 13.
} 
Michel Vincineau était un homme de combats. Il s'est investi sans relâche dans les luttes pour le désarmement, les atteintes à l'environnement, la défense des peuples soumis à l'occupation étrangère ou à des régimes dictatoriaux (le Sahara occidental, la Palestine, le Chili ...) ou les exclusions sociales. Il joua un rôle significatif dans les Journées universitaires de la Paix lancées par le Pôle Bernheim.

Mais le combat le plus notoire de Michel Vincineau, celui pour lequel il paya de sa personne, fut la défense des homosexuels masculins ou féminins. Il fut à l'origine de l'abolition d'une disposition du code pénal qui discriminait la majorité sexuelle selon qu'il s'agissait d'une relation hétéro- ou homosexuelle, fixée à 16 ans pour la première, 18 ans pour la seconde. Il créa aussi une ASBL pour lutter contre le SIDA («Aide info SIDA »), maladie qui avait emporté plusieurs de ses amis. Enfin, il acquit une renommée dont il se serait bien passé en participant à l'ouverture d'un sauna qui était un lieu de rencontre pour homosexuels : le Macho à Anvers et le Macho II à Bruxelles. Cela lui valut des poursuites pénales pour tenue de maison de débauche et, même, une détention préventive de près de quatre mois à Saint-Gilles. L'ULB n'hésita pas à dénoncer publiquement ces poursuites. Michel Vincineau devait tirer de cette odieuse expérience une étude approfondie de la loi belge sur la notion de « débauche »: La débauche en droit et droit à la débauche (Editions de l'Université de Bruxelles, 1985). Défendu par Roger Lallemand et Pierre Legros, il fut acquitté en première instance mais condamné par la Cour d'appel de Bruxelles par des motifs inscrits au panthéon de la littérature discriminatoire : " il ressort que ce qui est constitutif de « débauche » dans le cas d'espèce, c'est bien le fait que des relations homosexuelles soient favorisées par des établissements de ce type. En effet (...), si l'homosexualité n'est pas, en elle-même, constitutive d'infraction, il n'en demeure pas moins qu'elle constitue une forme de dérèglement de la sexualité par cela seul qu'elle méconnaît la finalité de l'existence de deux sexes différents, finalité dont l'abandon généralisé mènerait à l'extinction de l'espèce humaine » ... ! Après cassation de cet arrêt, l'affaire revint devant la Cour d'appel de Liège où il fut acquitté dans les termes suivants : « Le dossier soumis à la cour permet seulement de retenir comme établies des relations d'ordre sexuel entre deux personnes majeures et consentantes, dénuées d'esprit de vénalité, dans un lieu clos et en dehors de la présence de tiers. A moins de discriminer l'homosexualité, des relations de ce genre ne peuvent être qualifiées de débauche ».

Michel Vincineau était un remarquable juriste : il avait un sens aigu de la logique et du militantisme juridique comme en témoignent ses écrits. C'était un homme cultivé, spirituel et joyeux de vivre, en dépit des drames qui ont assombri le cours de sa vie. C'était aussi un homme de plume : à 16 ans, il s'était amusé à composer un sonnet à la manière de Hérédia sur Zénobie, reine de Palmyre, poème que son professeur de français se plaisait à lire en classe comme modèle littéraire. Michel Vincineau s'essaya aussi au théâtre avec un succès inégal, même si l'une de ses pièces fut représentée à Paris au théâtre de la Michodière.

Sa vie professionnelle et affective pourrait donner lieu à une dramaturgie ou à un opéra qu'on aimerait représenter à Villers-la-Ville, Epidaure ou La Fenice. Nul doute que là où se trouve Michel, il s'en occupe déjà... 